\title{
Exogenous S1P Exposure Potentiates Ischemic Stroke Damage That Is Reduced Possibly by Inhibiting S1P Receptor Signaling
}

\author{
Eunjung Moon, ${ }^{1}$ Jeong Eun Han, ${ }^{1}$ Sejin Jeon, ${ }^{2}$ Jong Hoon Ryu, ${ }^{2}$ \\ Ji Woong Choi, ${ }^{1}$ and Jerold Chun ${ }^{3}$ \\ ${ }^{1}$ Laboratory of Neuropharmacology, College of Pharmacy and Gachon Institute of Pharmaceutical Science, Gachon University, \\ Yeonsu-gu, Incheon 406-799, Republic of Korea \\ ${ }^{2}$ Department of Oriental Pharmaceutical Science, College of Pharmacy, Kyung Hee University, Seoul 130-701, Republic of Korea \\ ${ }^{3}$ Department of Molecular Biology, Dorris Neuroscience Center, The Scripps Research Institute, La Jolla, CA 92037, USA
}

Correspondence should be addressed to Ji Woong Choi; pharmchoi@gachon.ac.kr and Jerold Chun; jchun@scripps.edu

Received 9 July 2015; Revised 18 September 2015; Accepted 28 September 2015

Academic Editor: Kazuyuki Kitatani

Copyright (C) 2015 Eunjung Moon et al. This is an open access article distributed under the Creative Commons Attribution License, which permits unrestricted use, distribution, and reproduction in any medium, provided the original work is properly cited.

\begin{abstract}
Initial and recurrent stroke produces central nervous system (CNS) damage, involving neuroinflammation. Receptor-mediated S1P signaling can influence neuroinflammation and has been implicated in cerebral ischemia through effects on the immune system. However, S1P-mediated events also occur within the brain itself where its roles during stroke have been less well studied. Here we investigated the involvement of S1P signaling in initial and recurrent stroke by using a transient middle cerebral artery occlusion/reperfusion (M/R) model combined with analyses of S1P signaling. Gene expression for S1P receptors and involved enzymes was altered during $M / R$, supporting changes in S1P signaling. Direct S1P microinjection into the normal CNS induced neuroglial activation, implicating S1P-initiated neuroinflammatory responses that resembled CNS changes seen during initial M/R challenge. Moreover, S1P microinjection combined with M/R potentiated brain damage, approximating a model for recurrent stroke dependent on S1P and suggesting that reduction in S1P signaling could ameliorate stroke damage. Delivery of FTY720 that removes S1P signaling with chronic exposure reduced damage in both initial and S1P-potentiated M/R-challenged brain, while reducing stroke markers like TNF- $\alpha$. These results implicate direct S1P CNS signaling in the etiology of initial and recurrent stroke that can be therapeutically accessed by S1P modulators acting within the brain.
\end{abstract}

\section{Introduction}

Cerebral ischemia produced during stroke is triggered by sudden lack of blood flow and subsequent reperfusion of the ischemic area. Within a few minutes of onset, neurons in the ischemic core are irreversibly injured, which in part determines the fate of brain tissue in the penumbra areas after stroke [1]. Brain damage results from a cascade of cellular and molecular events, including energy failure, excitotoxicity, oxidative stress, and neuroinflammation [2], the latter of which is characterized by CNS infiltration of immune cells and activation of neuroglia such as microglia and astrocytes; neuroinflammation also results in the production of a variety of neurotoxic molecules, including proinflammatory cytokines, all of which produce brain damage $[1,3,4]$.
Recurrent stroke, which is a common sequel to an initial stroke, leads to worsened patient outcomes and is thought to be a major cause of morbidity and mortality among initial stroke survivors. Neuroinflammation has been associated with an increased risk of recurrent stroke following transient ischemic attack and may contribute to more severe damage [5-10]. Several proinflammatory factors have been reported to be active in recurrent stroke, including IL- 6 , TNF- $\alpha$, lipoprotein-associated phospholipase $\mathrm{A}_{2}$, C-reactive protein, and fibrinogen $[9,11-14]$.

Another molecule implicated in neuroinflammation is the lysophospholipid known as sphingosine 1-phosphate (S1P), produced by the phosphorylation of sphingosine by two kinases, sphingosine kinases 1 and 2 (SPHK1 and SPHK2) [15], which acts predominantly as an extracellular signaling 
molecule through 5, cognate $G$ protein-coupled receptors [16]. This lipid signaling system has been extensively studied in neuroinflammatory processes associated with multiple sclerosis (MS) [17-20] through actions on both immune and CNS cells, where reductions in signaling promote therapeutic efficacy [21-26]. In addition to MS, S1P signaling has also been implicated in other CNS pathologies including Sandhoff disease and demyelination [21, 26-30]. Prior reports implicated S1P signaling in cerebral ischemia where it was presumed to act through effects on immune cells, including elevated S1P levels [31] and that the nonselective S1P receptor modulator, FTY720 (fingolimod), a current therapy for MS [17-20], reduces brain damage in cerebral ischemia [3236]. Intriguingly, fingolimod improved outcomes in a proofof-concept clinical trial of 23 patients with intracerebral hemorrhage at both acute (days) and chronic (months) time points [37], consistent with S1P signaling effects in human stroke.

In this study, we have assessed the possibility of direct CNS S1P receptor signaling in M/R models of stroke and focusing on changes occurring within the brain. We report that local increases in S1P within the brain potentiate damage produced by transient focal cerebral ischemia $(M / R)$, which may represent a new model for recurrent stroke, particularly in view of the effects on markers like TNF- $\alpha$. Importantly, we report that S1P receptor modulation using FTY720 can reduce stroke damage in both primary and recurrent stroke models.

\section{Materials and Methods}

2.1. Animals. All animal experiments were conducted in accordance with the Center of Animal Care and Use (CACU) guidelines of Lee Gil Ya Cancer and Diabetes Institute (LCDI) at Gachon University (numbers of approved animal protocols: LCDI-2012-0075 and LCDI-2014-0016). Adult male ICR mice (28-32 g, 7 weeks old) were purchased from the Orient Co., Ltd. (Korea), and were housed under controlled temperature $\left(22 \pm 2^{\circ} \mathrm{C}\right)$, constant humidity, and a $12 \mathrm{~h}$ light/dark cycle (light on 07:00-19:00), with food and water made available ad libitum. After S1P microinjection or middle cerebral artery occlusion (MCAO) and reperfusion (M/R) surgery (Figure 1, experimental scheme), mice were housed 4 per cage with moist food and soft bedding materials to reduce suffering until they were sacrificed by $\mathrm{CO}_{2}$ inhalation or used for sampling.

2.2. Materials. S1P [D-erythro-sphingosine-1-phosphate] was purchased from Avanti Polar Lipid (Alabaster, AL). FTY720 [2-amino-2-[2-(octyl-phenyl) ethyl]-1,3-propanediol hydrochloride] was kindly provided by Novartis AG (Basel). 2,3,5-Triphenyltetrazolium (TTC), 3,3'-diaminobenzidine tetrahydrochloride (DAB), fatty-acid-free BSA (FAFBSA), mouse monoclonal anti-glial fibrillary acidic protein (GFAP) antibody, anti- $\beta$-actin antibody, cresyl violet acetate, and protease inhibitor cocktail were purchased from SigmaAldrich (St. Louis, MO). Silicon (Variotime) and Zoletil 50 were obtained from Heraeus Kulzer GmbH (Germany)

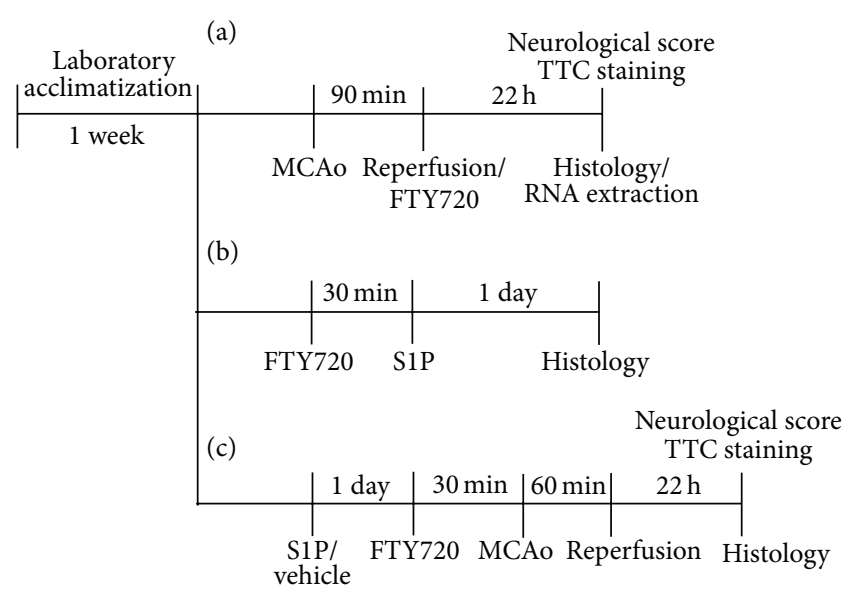

FIGURE 1: Schematic representation of experimental protocols. (a) Scheme for Figures 2 and 4 (an initial stroke model). Mice were challenged by $90 \mathrm{~min}$ occlusion followed by $22 \mathrm{~h}$ reperfusion. FTY720 (3 mg/kg, i.p.) was administered to mice immediately after reperfusion. (b) Scheme for Figure 3. S1P was microinjected into the corpus callosum (CC) and brain samples were prepared 1 day after microinjection. FTY720 was administered $30 \mathrm{~min}$ prior to S1P microinjection. (c) Scheme for Figures 5 to 7 (a recurrent strokemimicking model). S1P was at first microinjected into the CC. One day later, mice were challenged by $60 \mathrm{~min}$ occlusion followed by $22 \mathrm{~h}$ reperfusion. FTY720 (3 mg/kg, i.p.) was administered to mice 30 min prior to MCAO.

and Virbac (Carros, France), respectively. Goat polyclonal anti-Ibal and rabbit polyclonal anti-TNF- $\alpha$ antibodies were purchased from Abcam (Cambridge, UK). Avidin-biotinperoxidase complex $(\mathrm{ABC})$ kit and Vectashield were purchased from Vector Laboratories, Inc. (Burlingame, CA). Fluoro-Jade B was purchased from Chemicon (Temecula, CA).

2.3. Microinjection of S1P at Corpus Callosum (CC). S1P was dissolved in DMSO with $1 \mathrm{~N}$ HCL $(95: 5 \mathrm{v} / \mathrm{v}, 20 \mathrm{mM})$ and diluted in $10 \%$ FAF-BSA to make a stock $(2 \mathrm{mM}$; $1 \mathrm{nmole} / 0.5 \mu \mathrm{L})$. S1P $(1 \mathrm{nmol} / 0.5 \mu \mathrm{L}$ dissolved in $10 \%$ FAFBSA) was injected at $0.1 \mu \mathrm{L} / \mathrm{min}$ into the right $\mathrm{CC}$ of mice anesthetized with the mixture of Zoletil $50(10 \mathrm{mg} / \mathrm{kg}$, i.m.) and Rompun ( $3 \mathrm{mg} / \mathrm{kg}$, i.m.). Stereotaxic coordinates were as follows: AP (anteroposterior) $=+0.9 \mathrm{~mm}$ anterior to bregma, $\mathrm{ML}($ mediolateral $)= \pm 1.0 \mathrm{~mm}$, and $\mathrm{DV}$ (dorsoventral) $=$ $-2.15 \mathrm{~mm}$. For control mice, 10\% FAF-BSA solution containing the same amount of DMSO and $\mathrm{HCl}$ was used as vehicle instead of S1P. These mice were used for additional experiments $24 \mathrm{~h}$ after microinjection, including $M / R$ challenge (60 min of MCAO) and histological analysis.

2.4. Induction of Transient Focal Cerebral Ischemia. M/Rinduced focal ischemia was produced by an intraluminal suture method as reported [38, 39]. Briefly, mice were anesthetized with $3 \%$ isoflurane in $\mathrm{N}_{2} \mathrm{O}$ and $\mathrm{O}_{2}(70: 30)$ and maintained on $1.5 \%$ isoflurane. MCAO was induced by inserting a $9 \mathrm{~mm}$ long 5-0 nylon monofilament coated with silicon from the bifurcation to the MCA. In general, 
blood flow was restored 90 or $60 \mathrm{~min}$ after MCAO by carefully withdrawing the monofilament to allow complete reperfusion of the ischemic area under anesthesia. The latter condition (60 min of MCAO) was used to determine damage in recurrent stroke-mimicking situations. Sham-operated animals underwent the same surgical procedure without insertion of nylon monofilament. During the surgery, body temperature was maintained at $37 \pm 0.5^{\circ} \mathrm{C}$ using a heating pad (Biomed S.L., Spain).

2.5. FTY720 Administration. FTY720 was dissolved in saline $(0.15 \mathrm{M} \mathrm{NaCl})$ and intraperitoneally (i.p.) administered into mice at $3 \mathrm{mg} / \mathrm{kg} 30 \mathrm{~min}$ before S1P microinjection or MCAO surgery to determine its effect on neuroinflammation via $\mathrm{S} 1 \mathrm{P}$ exposure or on brain damage by $\mathrm{S} 1 \mathrm{P}+\mathrm{M} / \mathrm{R}$ challenge. Alternatively, FTY720 was administered to mice immediately after reperfusion to determine its therapeutic effect in $90 \mathrm{~min}$ $\mathrm{M} / \mathrm{R}$-challenged mice. For the control group, an equal volume of saline was administered.

\subsection{Measurement of Functional Neurological Deficit Score} and Infarct Volume. Twenty-two hours after reperfusion, the neurological functions of mice were assessed, including motor function, sensory function, reflex, and balance, using a well-known modified neurological severity score (mNSS), as described previously $[39,40]$.

Brains obtained $22 \mathrm{~h}$ after reperfusion were used to measure infarct volume by staining brain sections $(2 \mathrm{~mm}$ thickness) with $2 \%$ TTC in saline for $30 \mathrm{~min}$. TTC-stained sections were photographed and analyzed using an image J software (National Institute of Mental Health, Bethesda, MD). The infarct volume (\%) was calculated for each mouse brain by dividing the lesion volume with the total volume.

2.7. Histology. Mice were anesthetized with the mixture of Zoletil 50 (10 mg/kg, i.m.) and Rompun ( $3 \mathrm{mg} / \mathrm{kg}$, i.m.) and perfused transcardially with ice-cold $50 \mathrm{mM}$ phosphate-buffered saline (PBS, $\mathrm{pH}$ 7.4) followed by $4 \%$ paraformaldehyde. The brains were removed, postfixed in $4 \%$ paraformaldehyde containing $30 \%$ sucrose solution (in $50 \mathrm{mM}$ PBS), and frozen with OCT solution. Cryostat sections $(20 \mu \mathrm{m})$ were used for staining or immunohistochemistry.

For the determination of cell survival or death, cryostat sections were processed for Nissl or Fluoro-Jade B staining as in our previous report [39].

Tissue sections were also used for immunohistochemistry as follows. Tissue sections were treated with $1 \%$ hydrogen peroxide in PBS for 15 min, blocked with 5\% normal serum containing $0.3 \%$ Triton- 100 , and labeled with primary antibodies, such as goat anti-Ibal (1:500), mouse anti-GFAP $(1: 500)$, or rabbit anti-TNF- $\alpha(1: 100)$ antibody. The sections were labeled with appropriate biotinylated antibodies $(1: 200)$ followed by incubation with $\mathrm{ABC}$ solution $(1: 100)$ and then developed with a solution containing $0.02 \% \mathrm{DAB}$ and $0.01 \%$ $\mathrm{H}_{2} \mathrm{O}_{2}$.

Images were taken from each section using a brightfield or fluorescent microscope equipped with a DP72 camera (Olympus Co., Tokyo, Japan). For quantification of immunopositive cells, brain sections of $3 \sim 5$ mice were analyzed: the number for a mouse brain section was taken after calculating a mean value from 3 images (20x) of each section.

\subsection{Quantitative Real-Time PCR ( $q R T-P C R)$ and Semiquanti-} tative RT-PCR. Total RNA was extracted using RNAiso Plus (Takara) from mouse brain hemisphere subjected to surgical procedure after perfusion with ice-cold PBS and cDNA was synthesized according to the manufacturer's protocols (AffinityScript reverse transcription). qRT-PCR was performed using a Stratagene Mx3005p (Agilent Technologies, Inc., USA) and SYBR Green PCR master mix (Agilent Technologies). Gene expression was quantified using the comparative threshold method and data were calculated as fold changes relative to each gene of sham group after normalization to a reference gene, $\beta$-actin. Alternatively, $2 x$ master mix (Takara, Japan) was used to conduct semiquantitative RT-PCR. The sequences of all primer sets are listed in Table 1.

2.9. Statistical Analysis. All data are presented as mean \pm SEM and statistical analysis was carried out using GraphPad Prism software (GraphPad Software Inc., San Diego, CA) as specified. Differences among the groups were analyzed by one-way ANOVA followed by Newman-Keuls test for multiple comparisons. Comparisons between the two groups were performed using paired Student's $t$-test. The statistical significance was set at $P<0.05$.

\section{Results}

3.1. Expression Levels of SIP Signaling-Related Genes Are Altered in M/R-Challenged Mouse Brain. We examined whether transient cerebral ischemia influences gene expression levels of S1P receptors $\left(\mathrm{S}_{1} \mathrm{P}_{1-5}\right)$ and S1P-producing enzymes (sphingosine kinase 1/2, SPHK1/2) within the brain. Temporal changes in S1P receptors and SPHK1/2 gene expression were assessed by qRT-PCR or semiquantitative RT$\mathrm{PCR}, 22 \mathrm{~h}$ after $\mathrm{M} / \mathrm{R}$ reperfusion, as compared to $\beta$-actin controls. In the normal mouse brain, 4 of 5 S1P receptors were expressed, including $\mathrm{S}_{1}, \mathrm{~S}_{1} \mathrm{P}_{2}, \mathrm{~S}_{1} \mathrm{P}_{3}$, and $\mathrm{SiP}_{5}$, with particularly high expression of $\mathrm{S}_{1} \mathrm{P}_{1}$ (Figure 2(a)). In M/Rchallenged brains, mRNA expression of $\mathrm{SIP}_{3}$ and SPHK1 was significantly upregulated compared with sham-operated brains, with differences 3- to 4-fold higher (Figure 2(b)). In contrast, $\mathrm{S}_{1} \mathrm{P}_{1}$ was downregulated in the $\mathrm{M} / \mathrm{R}$ group (Figure 2(b)). When semiquantitative RT-PCR analysis was employed, $\mathrm{S}_{1} \mathrm{P}_{1}$ downregulation was confirmed as observed in data from qRT-PCR analysis. Interestingly, the lowered expression level of $\mathrm{S}_{1} \mathrm{P}_{1}$ was still higher than the upregulated $\mathrm{S} \mathrm{P}_{3}$ in M/R-challenged brains (Figure 2(c)). These results indicate that S1P receptor expression is altered by cerebral ischemia.

3.2. Local SIP Microinjection Activates Microglia and Astrocytes. Local injection of S1P into the brain induces astrocyte activation [23], which may have relevance to cerebral 
TABLE 1: Primers used for PCR analysis.

\begin{tabular}{|c|c|c|c|}
\hline Gene & Direction & Sequence & Gene accession number \\
\hline \multirow{2}{*}{$\beta$-actin } & Forward & $5^{\prime}$-AGCCTTCCTTCTTGGGTATG-3' & \multirow{2}{*}{ NM_007393 } \\
\hline & Reverse & $5^{\prime}$-CTTCTGCATCCTGTCAGCAA-3' & \\
\hline \multirow{2}{*}{ S1pr1 } & Forward & $5^{\prime}$-AGGGAACTTTGCGAGTGAG-3' & \multirow{2}{*}{ NM_007901 } \\
\hline & Reverse & $5^{\prime}$-GTTACAGCAAAGCCAGGTCAG-3' & \\
\hline \multirow{2}{*}{ S1pr2 } & Forward & $5^{\prime}$-ATAGACCGAGCACAGCCAAC-3' & \multirow{2}{*}{ NM_010333 } \\
\hline & Reverse & $5^{\prime}$-GTGTTCCAGAACCTTCTCAGG-3' & \\
\hline \multirow{2}{*}{ S1pr3 } & Forward & 5'-TTGCAGAACGAGAGCCTATT-3' $^{\prime}$ & \multirow{2}{*}{ NM_010101 } \\
\hline & Reverse & $5^{\prime}$-TTCCCGGAGAGTGTCATTTC-3' & \\
\hline \multirow{2}{*}{ S1pr4 } & Forward & 5'-ACCTTCAGTCTGCTCTTCACG-3' & \multirow{2}{*}{ NM_010102 } \\
\hline & Reverse & 5'-AAGAGCACATAGCCCTTGGAG-3' & \\
\hline \multirow{2}{*}{ S1pr5 } & Forward & $5^{\prime}$-AGATTTCCAATAGCCGCTCTC-3' & \multirow{2}{*}{ NM_053190 } \\
\hline & Reverse & 5'-AGCTTGCCGGTGTAGTTGTAG-3' & \\
\hline \multirow{2}{*}{ Sphk1 } & Forward & 5'-AGTCATGTCCGGTGATGGTC-3' & \multirow{2}{*}{ NM_011451 } \\
\hline & Reverse & $5^{\prime}$-CCAGTTGGCCTTGGTAGATG-3' & \\
\hline \multirow{2}{*}{ Sphk2 } & Forward & $5^{\prime}$-ATCTCTGAAGCTGGGCTGTC-3' & \multirow{2}{*}{ NM_203280 } \\
\hline & Reverse & $5^{\prime}$-GAAGAAGCGAGCAGTTGAGC-3' & \\
\hline
\end{tabular}

ischemia in view of changes to S1P signaling molecules. To determine whether direct activation of S1P receptors induces changes in activation of microglia and astrocytes, immunohistochemistry was used to assess the microglia/macrophagespecific marker Ibal or the astrocyte-specific marker GFAP. S1P microinjection was used to localize S1P at the level of the corpus callosum via defined stereotaxic coordinates (see Section 2) to produce uniform and reproducible exposure. Immunohistochemistry of normal, injected brains revealed increased Ibal-immunopositive cell numbers as compared with vehicle-injected controls $(18.50 \pm 11.36$ to $67.80 \pm 11.41$ : $370 \%$ ) (Figure 3(a)). In addition, S1P microinjection induced an increase in GFAP-immunopositive cells (116.4 \pm 14.91 to $244.4 \pm 59.45: 210 \%$ ) (Figure 3(b)). These neuroinflammatory outcomes were reduced by pretreatment of FTY720 $(3 \mathrm{mg} / \mathrm{kg}$, i.p.; Figure 3), a nonselective S1P receptor modulator that acts as a functional antagonist of, at least, $\operatorname{S1P}_{1}[17,36]$. These results indicate that activation of S1P receptors induces neuroinflammatory changes for neuroglia that can be prevented by pharmacological modulation of S1P receptor activities.

\subsection{FTY720 Reduces $M / R$-Induced Brain Infarction and Neu-} roglial Activation. To determine the role of S1P receptor signaling in the pathogenesis of cerebral ischemia, mice were challenged by $\mathrm{M} / \mathrm{R}$ ( $90 \mathrm{~min}$ of occlusion) and compared to the same challenge except that animals were exposed to FTY720 (3 mg/kg, i.p.) immediately after reperfusion. Brain damage as a percentage of total brain was then assessed by TTC staining of sampled serial sections from the entire brain taken $22 \mathrm{~h}$ later (Figures $4(\mathrm{a})$ and $4(\mathrm{~b})$ ). M/R induced brain infarction by $28.08 \pm 2.347 \%$, which was reduced by FTY720 administration to $22.00 \pm 1.586 \%$ (Figure $4(\mathrm{~b})$ ). Brain damage was also determined $22 \mathrm{~h}$ after reperfusion based on neurological score, showing that FTY720 exposure recovered damaged neurological functions in cerebral ischemia (Figure 4(c)). Neuroglial activation was assessed in
$\mathrm{M} / \mathrm{R}$ groups treated with saline $(\mathrm{M} / \mathrm{R}+\mathrm{sal})$ or FTY720 (M/R + FTY720) (Figures 4(d) and 4(e)). M/R-challenged mice displayed microglial activation (Ibal-immunopositive cells, Figure 4(d)) and astrogliosis (GFAP-immunopositive cells, Figure 4(e)), which were both markedly decreased in $M / R$ + FTY720 group compared with saline-treated M/R group controls. These data demonstrate that FTY720 significantly decreases brain damage in $\mathrm{M} / \mathrm{R}$-challenged mice that is associated with reduced astrocyte and microglial activation, supporting S1P receptor signaling in the brain as a pathological mediator of cerebral ischemia that can be altered to reduce neuroinflammatory changes and brain damage produced by $\mathrm{M} / \mathrm{R}$.

3.4. Brain Damage Is Augmented by S1P Microinjection. Neuroinflammation during initial cerebral ischemia is strongly correlated with recurrent cerebral ischemia, in which more severe brain damage occurs [7-10]. Based on findings that $\mathrm{S} 1 \mathrm{P}$ receptors are involved in neuroglial activation and $\mathrm{M} / \mathrm{R}-$ induced damage, S1P microinjection was used to activate local neuroglia followed by $M / R$ challenge followed by assessments of brain damage. To determine the augmentation clearly, mice were challenged by a shorter M/R (60 min of occlusion and reperfusion) 24 hours after S1P microinjection. S1P microinjection followed by M/R (S1P + M/R) significantly increased damage compared to $M / R$ after vehicle injection (veh + M/R) (Figures 5(a) and 5(b)). Cerebral infarct volume in veh $+M / R$ group was $18.40 \pm 3.638 \%$ whereas the $\mathrm{S} 1 \mathrm{P}+\mathrm{M} / \mathrm{R}$ group was $29.57 \pm 4.867 \%$ (Figure $5(\mathrm{~b})$ ). This secondary, augmented brain damage produced by initial S1P microinjection was reduced by FTY720 administration prior to $\mathrm{M} / \mathrm{R}$ challenge (Figures 5(a) and 5(b)). Infarct volume in the S1P + FTY + M/R group was $16.73 \pm 2.493$ (Figure 5(b)). These results were confirmed by assessments of neurological deficit (Figure 5(c)) and neural cell death using Fluoro-Jade B staining (Figure 5(d)). These data showed 


\begin{tabular}{|c|c|c|c|c|c|}
\hline ש & & $x=$ & & $--=$ & --- \\
\hline S1pr1 & S1pr2 & S1pr3 & S1pr4 & S1pr5 & $\beta$-actin \\
\hline
\end{tabular}

(a)

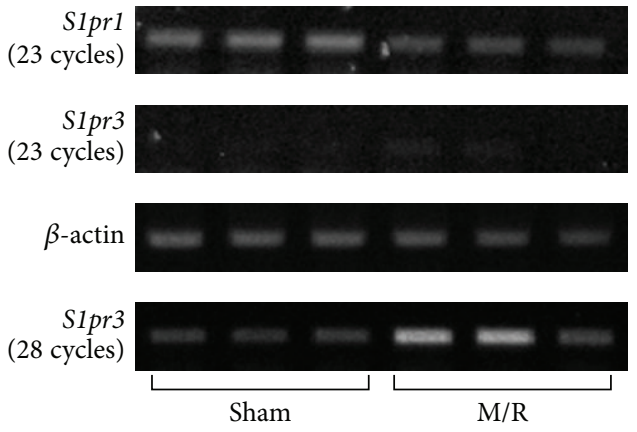

(c)

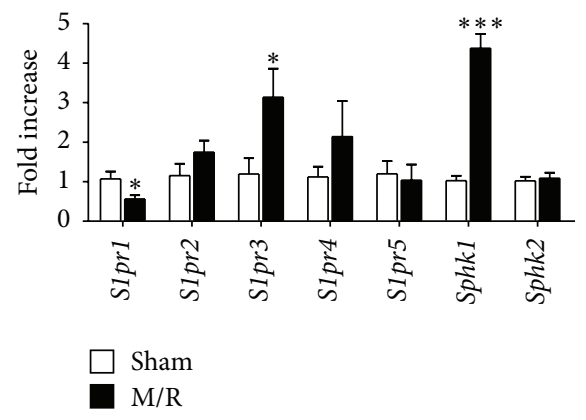

(b)

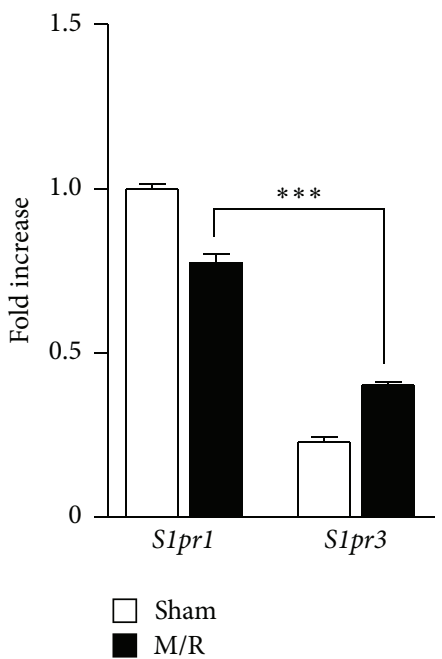

FiguRE 2: mRNA expression levels of S1P receptors and S1P-producing enzymes are altered in an M/R-challenged brain. (a) Normal brains were used to determine mRNA expression levels of S1P receptors (S1pr1, S1pr2, S1pr3, S1pr4, and S1pr5) and SPHKs (Sphk1 and Sphk2) based on semiquantitative RT-PCR analysis ( 28 cycles for all targets). (b, c) Mice were challenged by 90 min occlusion followed by $22 \mathrm{~h}$ reperfusion. (b) Brain samples were used to determine changes of S1P receptors and SPHKs based on qRT-PCR analysis. ${ }^{*} P<0.05$ and ${ }^{* * *} P<0.001$, compared with the sham group ( $t$-test), $n=5$ per group. (c) Brains from sham and M/R-challenged mice were used to determine mRNA expression levels of $\mathrm{S}_{1} \mathrm{P}_{1}$ and $\mathrm{SiP}_{3}$ by semiquantitative RT-PCR analysis. Band intensity (bar graph) was calculated as fold increase relative to S1pr1 level of sham groups after normalization to $\beta$-actin. ${ }^{* * *} P<0.001$, compared with S1prl level of M/R group (Newman-Keuls test), $n=3$ per group.

that the increased brain damage in S1P $+\mathrm{M} / \mathrm{R}$ group was blocked by FTY720 administration and indicated that S1P receptor signaling that activates neuroglia-astrocytes and microglia-exacerbates M/R-induced brain damage, possibly representing a model for increased damage observed in recurrent cerebral ischemia.

3.5. FTY720 Reduces Neuroglial Activation Occurring in S1PPrimed $M / R$ Challenge. Local S1P microinjection augmented $\mathrm{M} / \mathrm{R}$ damage, indicating that CNS S1P receptor signaling potentiates damage produced by ischemic insult. To determine whether local neuroglial activation was also occurring in S1P-primed damage, activated microglia and astrocytes were examined using immunohistochemical markers from animals challenged under various $M / R$ conditions as compared to sham controls. Immunohistochemically observed microglial activation (Ibal-immunopositive cells, Figure 6(a)) and astrogliosis (GFAP-immunopositive cells,
Figure 6(b)) were both increased in $\mathrm{S} 1 \mathrm{P}+\mathrm{M} / \mathrm{R}$ group compared to the $M / R$ only group (veh $+M / R$ ) and sham controls. The activation was then assessed in animals that had received FTY720 administration prior to M/R challenge: this reduced activation of microglia and astrocytes $(\mathrm{S} 1 \mathrm{P}+\mathrm{FTY}+\mathrm{M} / \mathrm{R})$ (Figure 6).

3.6. S1P Microinjection Induces TNF- $\alpha$ Expression. The priming of $\mathrm{M} / \mathrm{R}$ damage by S1P microinjection into the brain was suggestive of changes seen in recurrent stroke, raising the question of whether markers for recurrent stroke might be expressed in the S1P-primed model. Increased TNF- $\alpha$ expression is associated with a risk of recurrent stroke [13]. TNF- $\alpha$ immunolabeling in the cortex identified significant increases in the number of cells expressing TNF- $\alpha$ after S1P microinjection alone $(\mathrm{S} 1 \mathrm{P})$ or $\mathrm{M} / \mathrm{R}$ alone (veh $+\mathrm{M} / \mathrm{R}$ ) (Figure 7). Notably, the number of TNF- $\alpha$-positive cells was 

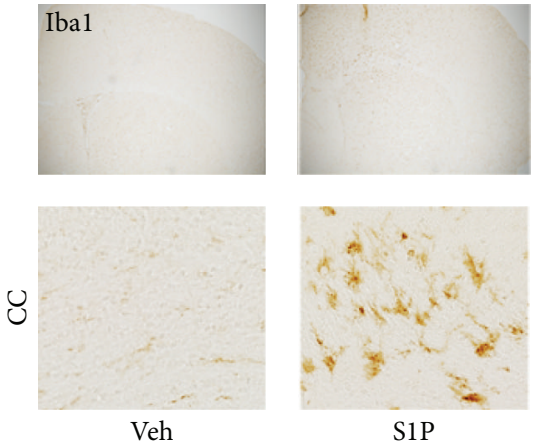

S1P
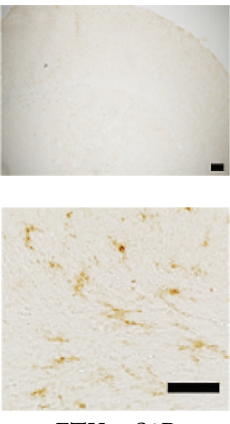

$\mathrm{FTY}+\mathrm{S} 1 \mathrm{P}$

(a)
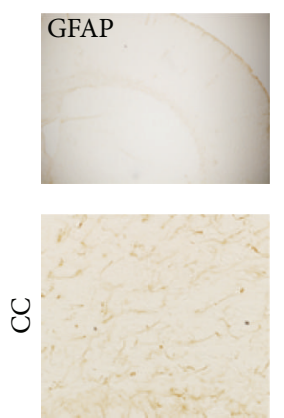

Veh
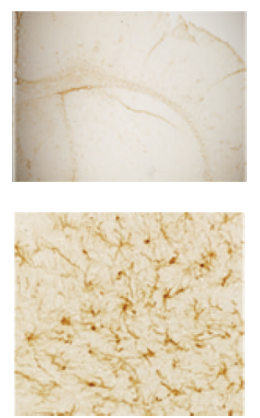

S1P
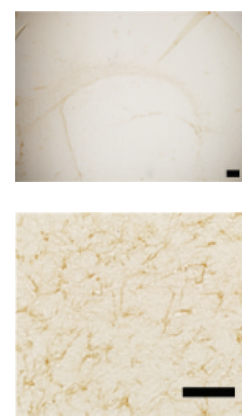

FTY + S1P
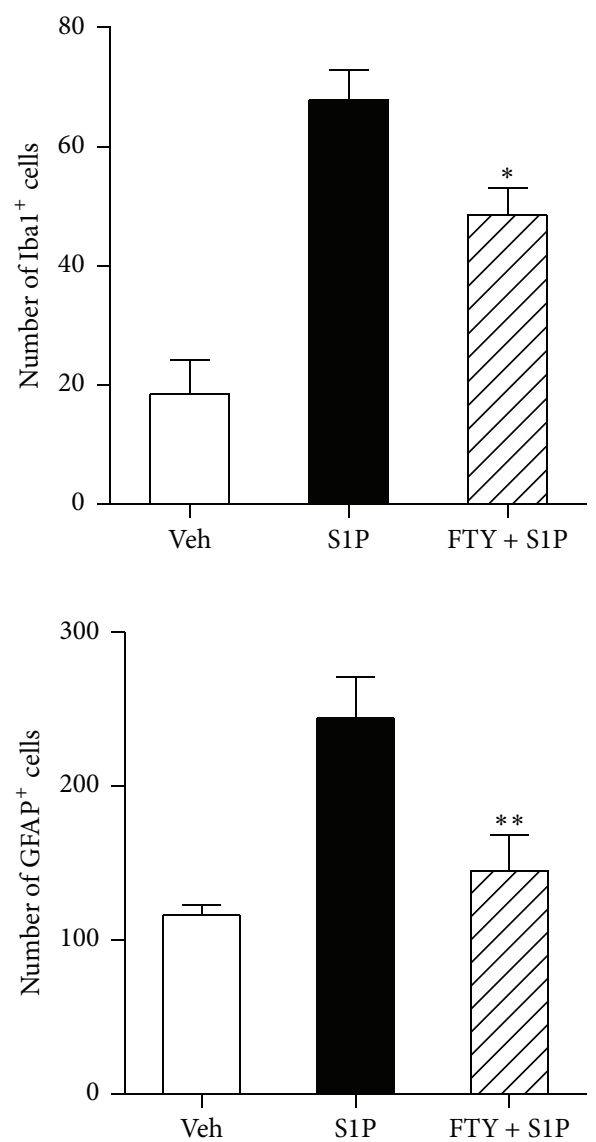

(b)

FIGURE 3: Microglia and astrocytes are activated in the brain following S1P microinjection into the corpus callosum. S1P was microinjected into the corpus callosum (CC), and activation of microglia or astrocytes was assessed 1 day after microinjection. FTY720 (FTY) was administered 30 min prior to S1P microinjection. Representative microphotographs of brain sections immunolabeled against Ibal (a) or GFAP (b) and their quantitative analysis in groups of vehicle (veh), S1P, and FTY + S1P. ${ }^{*} P<0.05$ and ${ }^{* *} P<0.01$, compared with the S1P-injected group (S1P) (Newman-Keuls test). $n=5$ per group. Scale bar, 200 (upper panel) or $50 \mu \mathrm{m}$ (lower panel).

highest in brains challenged by $\mathrm{M} / \mathrm{R}$ after initial S1P microinjection $(\mathrm{S} 1 \mathrm{P}+\mathrm{M} / \mathrm{R})$ (Figure 7$)$. All conditions showed a reduction in TNF- $\alpha$ expression following FTY720 exposure $(\mathrm{FTY}+\mathrm{S} 1 \mathrm{P}$ and S1P + FTY $+\mathrm{M} / \mathrm{R})$ (Figure 7$)$. These data indicate that S1P receptor-mediated changes can produce pathological changes consistent with recurrent stroke, which can be reduced by modulation of S1P signaling by FTY720 exposure.

\section{Discussion}

The present study has identified activation of S1P receptor signaling within the brain as a factor in transient focal cerebral ischemic (M/R) brain damage, particularly involving activation of astrocytes and microglia. In particular, local brain delivery of $\mathrm{S} 1 \mathrm{P}$ - which is independent of $\mathrm{M} / \mathrm{R}$, produced astrocyte, and microglial activation - was found to potentiate ischemic brain damage, supporting direct CNS activities of S1P signaling in stroke. FTY720 reduced neuroglial activation and ischemic brain damage and this neuroprotective effect was associated with neuroinflammation [41, 42] wherein neuroglia, such as astrocytes and microglia, are activated by immune cells within the CNS. These data implicate modulation of S1P receptors in forms of stroke, including recurrent stroke, which can be therapeutically accessed by S1P receptor modulation.

Receptor-mediated S1P signaling has previously been suggested to play a role in cerebral ischemia based upon protective effects of the S1P receptor modulator, FTY720. In rodent models of cerebral ischemia, FTY720 reduced ischemic brain damage [32-36], with consistent results observed in a proof-of-concept clinical trial that reported improved neurological endpoints with FTY720 (fingolimod) treatment of brain hemorrhagic stroke patients [37]. The proposed mechanism of FTY720 efficacy in stroke models [36] was similar to that initially proposed for multiple sclerosis (MS) wherein a reduction of pathogenic lymphocytes entering the brain occurs, produced by S1P-dependent alterations of lymphocyte trafficking [18]. This effect is consistent with reported lymphocyte involvement in cerebral ischemia [35].

In addition, evidence for nonimmunological S1P signaling mechanisms occurring within the brain itself has 

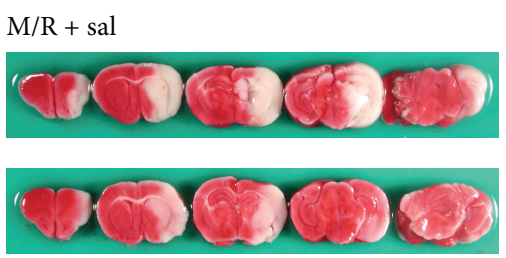

$\mathrm{M} / \mathrm{R}+\mathrm{FTY}$

(a)
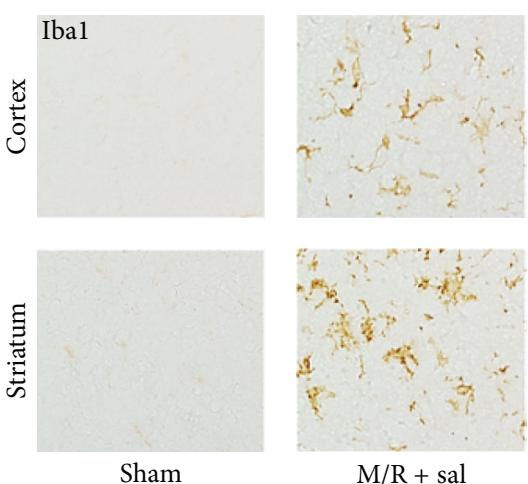

$\mathrm{M} / \mathrm{R}+\mathrm{sal}$

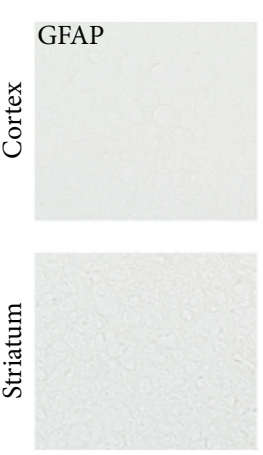

Sham
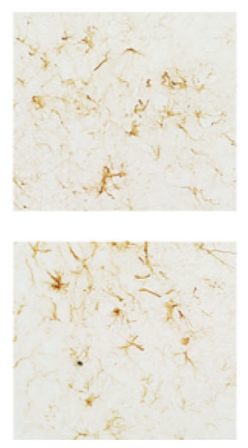

$\mathrm{M} / \mathrm{R}+\mathrm{sal}$

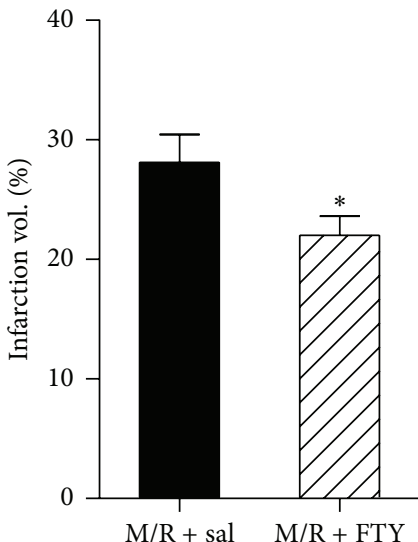

(b)
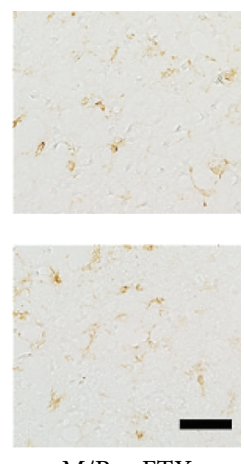

$\mathrm{M} / \mathrm{R}+\mathrm{FTY}$

(d)

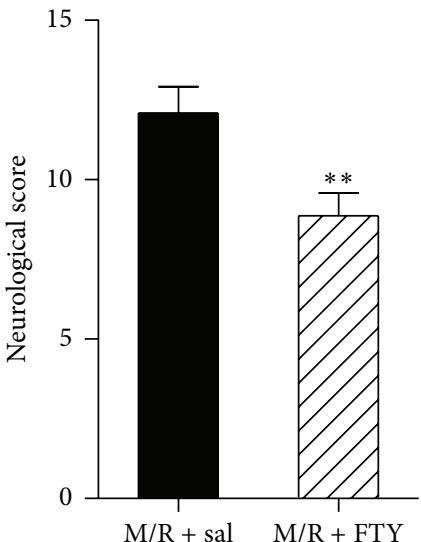

(c)
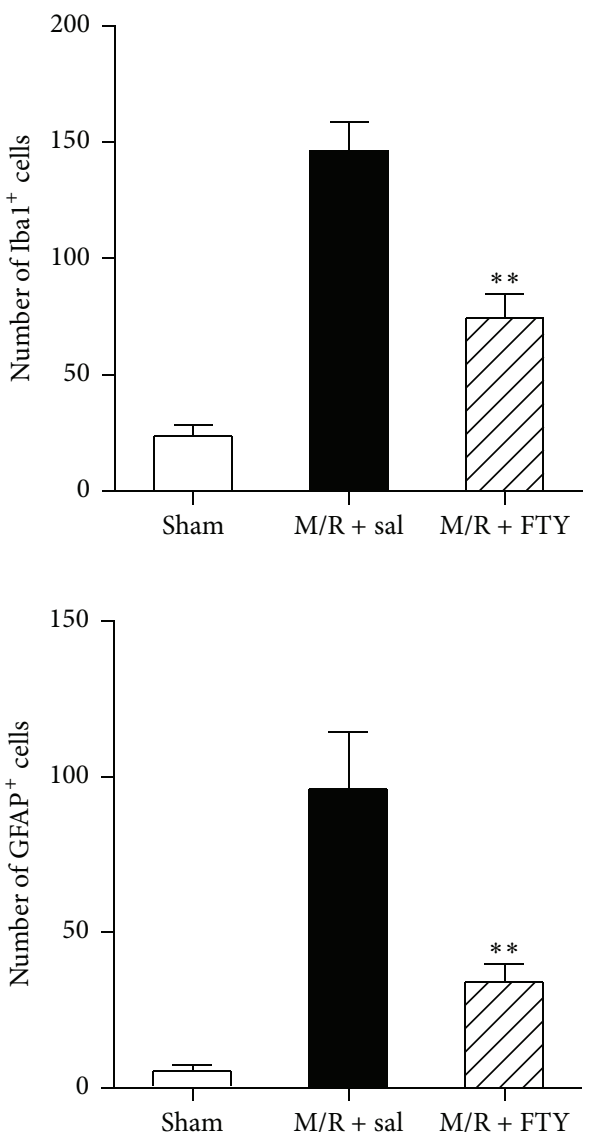

(e)

FIGURE 4: FTY720 reduces brain damage and neuroinflammation in M/R-challenged mice. Mice were challenged by 90 min occlusion and brain infarction or neuroinflammation was assessed $22 \mathrm{~h}$ after reperfusion. FTY720 (FTY, $3 \mathrm{mg} / \mathrm{kg}$, i.p.) was administered to mice immediately after reperfusion. (a) Representative TTC-stained brain slices of M/R + saline (sal) and M/R + FTY. Photographs are coronal brain sections stained with TTC showing infarct area (white) and intact area (red). (b) Percentage of infarct volumes calculated from the TTC-stained brain slices. Infarct volume was measured using Image J software, and the percentage of infarction was assessed. (c) Neurological score demonstrating neurological functions. ${ }^{*} \mathrm{P}<0.05$ ( $t$-test), compared with the saline-treated group (M/R + sal) $(t$-test). $n=12 \sim 15$ per group. $(d, e)$ Representative microphotographs of cortex and striatum regions immunolabeled against Ibal (d) or GFAP (e) and their quantitative analysis in groups of sham, M/R + sal, and M/R + FTY. ${ }^{* *} P<0.01$, compared with the saline-treated group (M/R + sal) of each set (NewmanKeuls test). $n=3$ per group. Scale bar, $50 \mu \mathrm{m}$. 


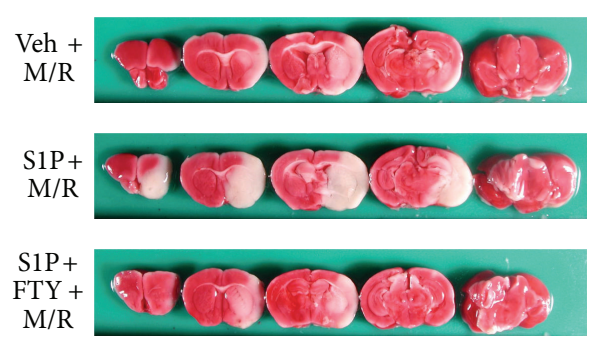

(a)
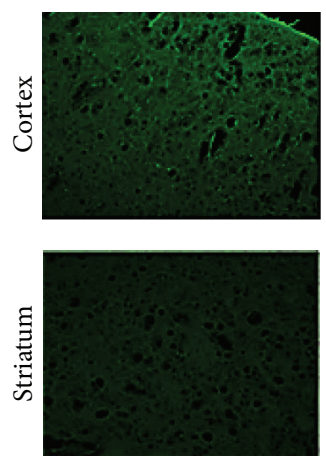

Sham

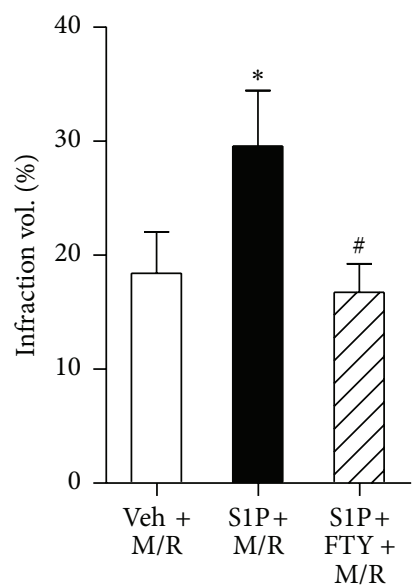

(b)
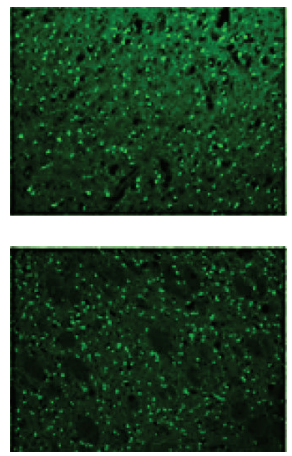

$\mathrm{Veh}+\mathrm{M} / \mathrm{R}$
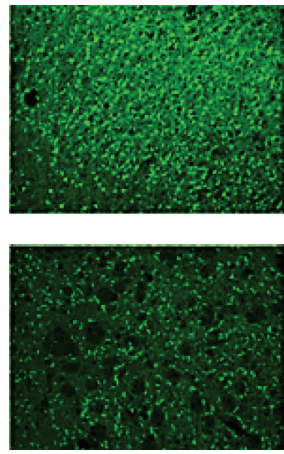

$\mathrm{S} 1 \mathrm{P}+\mathrm{M} / \mathrm{R}$

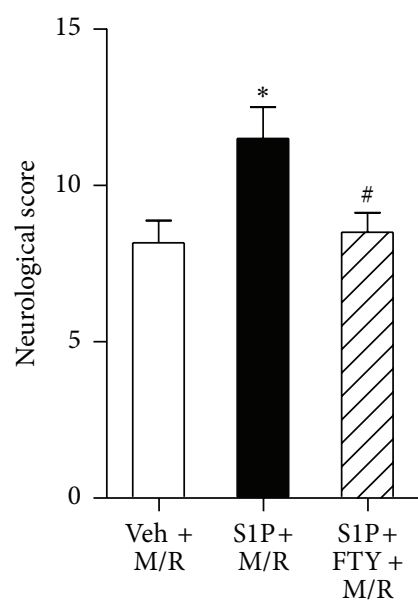

(c)
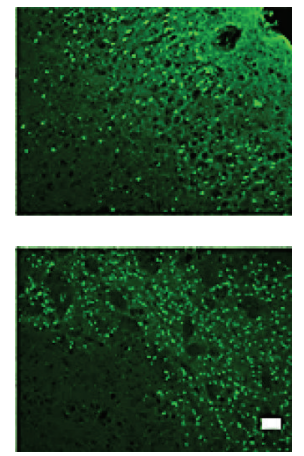

$\mathrm{S} 1 \mathrm{P}+\mathrm{FTY}+\mathrm{M} / \mathrm{R}$

(d)

FIGURE 5: Activation of S1P signaling induces augmented brain damage following M/R injury. S1P or vehicle (veh) was microinjected into the corpus callosum $24 \mathrm{~h}$ prior to M/R challenge ( $60 \mathrm{~min}$ occlusion followed by $22 \mathrm{~h}$ reperfusion). FTY720 (FTY) was administered into mice $30 \mathrm{~min}$ prior to $60 \mathrm{~min}$ occlusion. Brain infarction or neuroinflammation was assessed $22 \mathrm{~h}$ after reperfusion. (a) Representative TTC-stained brain slices of veh $+M / R, S 1 P+M / R$, and S1P + FTY $+M / R$. Photographs are coronal brain sections stained with TTC showing infarct area (white) and intact area (red). (b) Percentage of infarct volumes calculated from the TTC-stained brain slices. Infarct volume was measured using Image J software and the percentage of infarction was assessed. (c) Neurological score demonstrating neurological functions. ${ }^{*} P<0.05$ and ${ }^{\#} P<0.05$, compared with the M/R group (veh $+M / R$ ) and S1P $+M / R$ group, respectively (Newman-Keuls test). $n=6 \sim 8$ per group. (d) Representative microphotographs of cortex and striatum regions stained with Fluoro-Jade B. Scale bar, $50 \mu \mathrm{m}$.

emerged as an explanation for FTY720 efficacy in MS [21, 26-30], which might also be relevant to stroke. Notably, selective removal of the S1P receptor subtype $\mathrm{S}_{1} \mathrm{P}_{1}$ from astrocytes was found to reduce astrogliosis, disease severity, and FTY720 efficacy in EAE (experimental autoimmune encephalomyelitis), an animal model of MS [26], despite the maintenance of $\mathrm{S}_{1} \mathrm{P}_{1}$ in the immune system. Reductions in astrogliosis observed here during FTY720 exposure support the operation of a similar protective mechanism involving astrocyte reductions in $\mathrm{S}_{1} \mathrm{P}_{1}$ signaling. These observations support a direct effect of S1P receptor signaling on the severity of damage produced during stroke, which may involve nonimmunological mechanisms relevant to neuroprotection or repair. Consistent with this possibility, a proof-of-concept clinical trial examining FTY720 effects on hemorrhagic stroke patients reported not only short-term effects that might be immunologically driven, but also longerterm neurological improvement (3 months after event) [37].
Future identification of specific S1P receptor subtypes beyond $\mathrm{S}_{1} \mathrm{P}_{1}$ and the involved CNS cell types, such as microglia, will assist in elucidating the precise mechanisms of FTY720 efficacy in cerebral ischemia models, which also appears to be relevant to the recurrent stroke model accessed by S1P pretreatment within the brain in view of both damage potentiation by S1P and the increased presence of recurrent stroke markers like TNF- $\alpha$.

Additional support for the importance of S1P signaling mechanisms relevant to stroke may come from studies on S1P itself and its biosynthetic enzymes, SPHK1 and SPHK2. In cerebral ischemia, S1P levels are increased [31] and S1Pproducing enzymes may be upregulated in lesion sites [43, 44] even with a contrasting report for the latter [34]. In the normal brain, SPHK2 is more abundantly expressed than SPHK1 [45] and is thought to play a protective role [46]. SPHK2 upregulation in the ischemic or hypoxic brain has been reported $[43,44]$ but requires further study in view of 

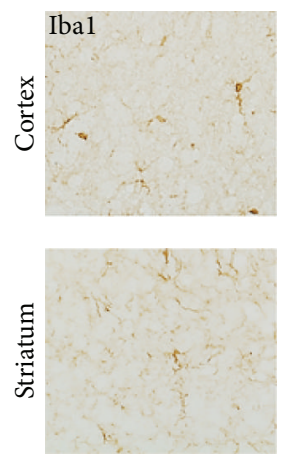

Sham
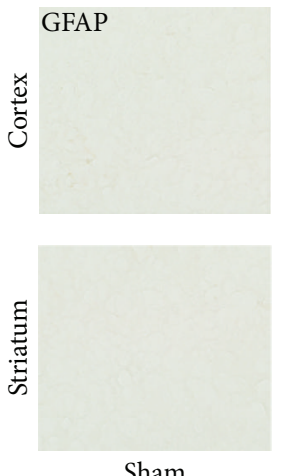

Sham
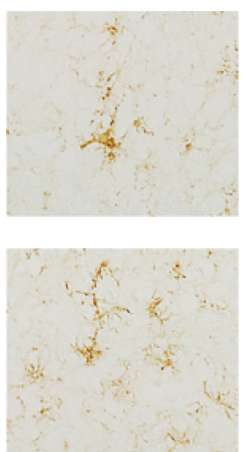

$\mathrm{Veh}+\mathrm{M} / \mathrm{R}$
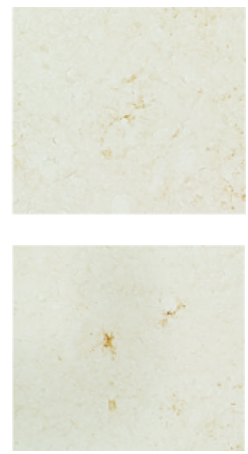

$\mathrm{Veh}+\mathrm{M} / \mathrm{R}$
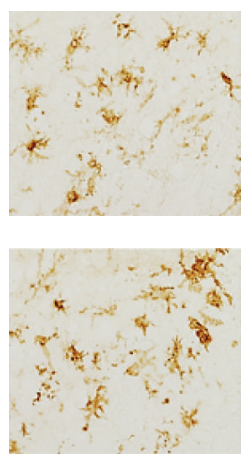

$\mathrm{S} 1 \mathrm{P}+\mathrm{M} / \mathrm{R}$
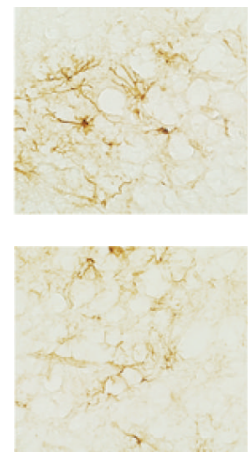

$\mathrm{S} 1 \mathrm{P}+\mathrm{M} / \mathrm{R}$
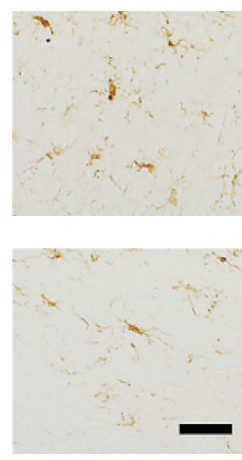

$\mathrm{S} 1 \mathrm{P}+\mathrm{FTY}+\mathrm{M} / \mathrm{R}$

(a)

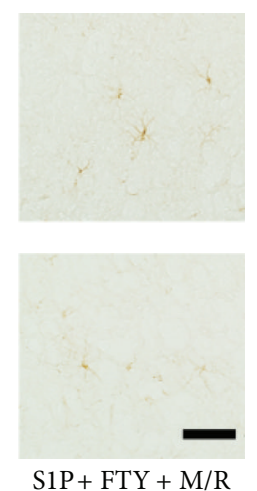

(b)
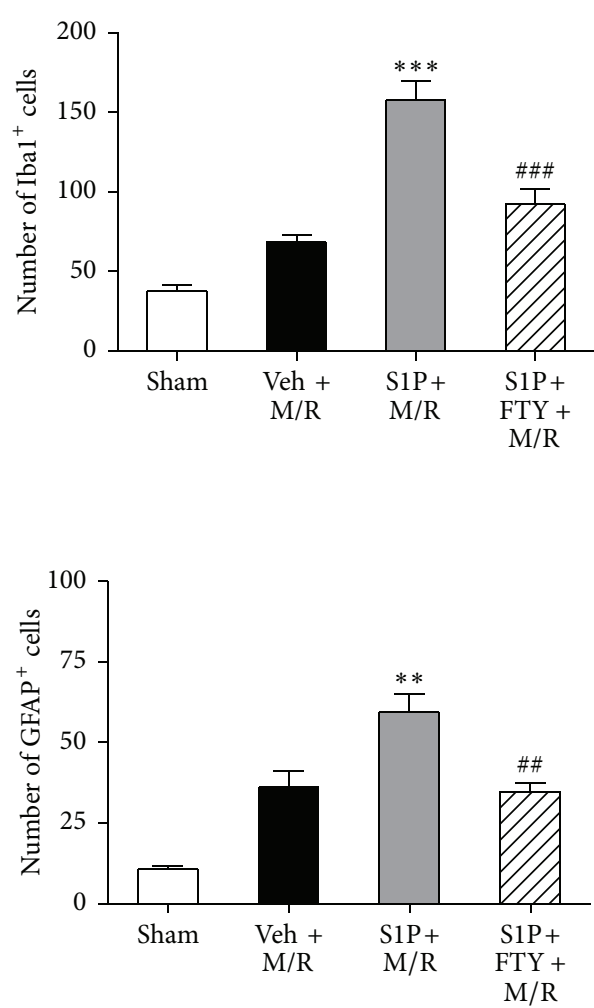

FIgURE 6: Activation of S1P signaling induces augmented microglial activation and astrogliosis following M/R injury. S1P or vehicle (veh) was injected into the corpus callosum $24 \mathrm{~h}$ prior to M/R challenge ( $60 \mathrm{~min}$ occlusion followed by $22 \mathrm{~h}$ reperfusion). FTY720 (FTY) was administered into mice $30 \mathrm{~min}$ prior to $60 \mathrm{~min}$ occlusion. Activation of microglia or astrocytes was assessed $22 \mathrm{~h}$ after reperfusion. Representative microphotographs of brain sections immunolabeled against Ibal (a) or GFAP (b) and their quantitative analysis in groups of sham, veh $+\mathrm{M} / \mathrm{R}, \mathrm{S} 1 \mathrm{P}+\mathrm{M} / \mathrm{R}$, and S1P $+\mathrm{FTY}+\mathrm{M} / \mathrm{R} .{ }^{* *} P<0.01$ and ${ }^{* * *} P<0.001$, compared with M/R group (veh $\left.+\mathrm{M} / \mathrm{R}\right)(\mathrm{Newman}-$ Keuls test). ${ }^{\# \#} P<0.01$ and ${ }^{\# \#} P<0.001$, compared with the S1P + M/R group (Newman-Keuls test). $n=3$ per group. Scale bar, $50 \mu \mathrm{m}$.

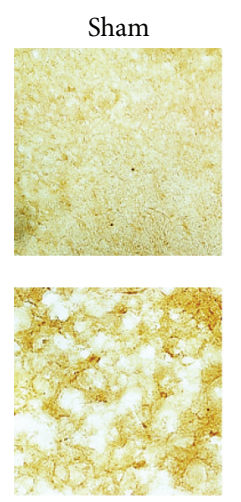

$\mathrm{Veh}+\mathrm{M} / \mathrm{R}$
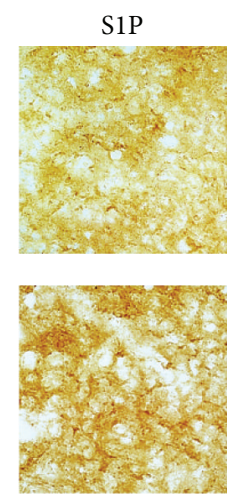

$\mathrm{S} 1 \mathrm{P}+\mathrm{M} / \mathrm{R}$

(a)

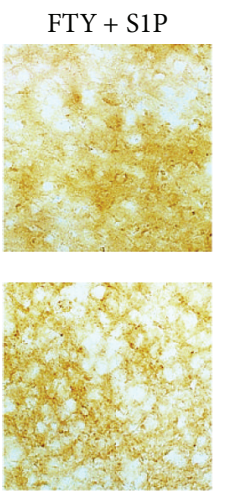

$\mathrm{S} 1 \mathrm{P}+\mathrm{FTY}+\mathrm{M} / \mathrm{R}$

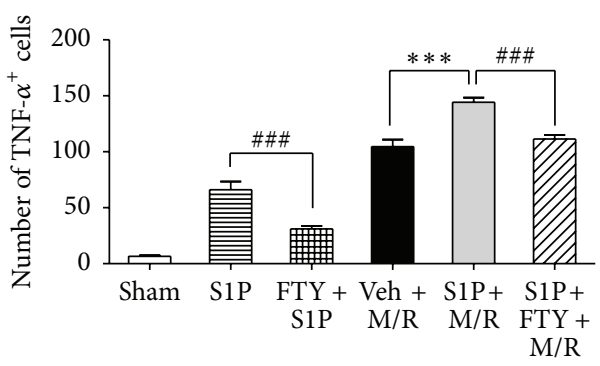

(b)

FIGURE 7: Activation of S1P signaling induces augmented TNF- $\alpha$ expression following M/R injury. S1P or vehicle (veh) was injected into the corpus callosum $24 \mathrm{~h}$ prior to M/R challenge ( $60 \mathrm{~min}$ occlusion followed by $22 \mathrm{~h}$ reperfusion). FTY720 (FTY) was administered into mice $30 \mathrm{~min}$ prior to S1P microinjection (FTY + S1P) or 60 min occlusion (S1P + FTY + M/R). Cells expressing TNF- $\alpha$ were assessed 1 day or $22 \mathrm{~h}$ after S1P microinjection or reperfusion. Representative microphotographs of brain sections immunolabeled against TNF- $\alpha$ (a) and their quantitative analysis (b) in groups of sham, S1P, FTY + S1P, veh $+M / R, S 1 P+M / R$, and S1P + FTY $+M / R$. Significance was presented only for the main groups as indicated. ${ }^{* * *} P<0.001$, compared with M/R group (veh $\left.+\mathrm{M} / \mathrm{R}\right)$ (Newman-Keuls test). ${ }^{\# \#} P<0.001$, compared with the S1P or S1P + M/R group (Newman-Keuls test). $n=3$ per group. Scale bar, $50 \mu \mathrm{m}$. 
a contrasting report that SPHK2 was not upregulated [34] and our finding that SPHK1 rather than SPHK2 was upregulated in the ischemic brain. Although this study suggests the importance of SPHK1 in cerebral ischemia based on its mRNA upregulation, a functional role of SPHK1 needs to be clarified. In addition to upregulation of ligand-producing enzyme, our data indicate altered mRNA expression levels of $\mathrm{S} 1 \mathrm{P}$ receptors, including $\mathrm{S}_{3}$ upregulation and $\mathrm{S}_{3} \mathrm{P}_{1}$ downregulation. It is of note that basal mRNA expression of $\mathrm{S}_{1} \mathrm{P}_{1}$ is much higher than $\mathrm{S}_{3} \mathrm{P}_{3}$ both in normal and $\mathrm{M} / \mathrm{R}$ stroke conditions and that the reduced expression level of $\mathrm{S}_{1} \mathrm{P}_{1}$ mRNA is still higher than the upregulated level of $\mathrm{S}_{3}$ in $\mathrm{M} / \mathrm{R}$. In fact, there is a report that $\mathrm{S}_{\mathrm{P}} \mathrm{P}_{1}$ is downregulated in the infarcted area $24 \mathrm{~h}$ following M/R challenge ( $2 \mathrm{~h}$ MCAo followed by $24 \mathrm{~h}$ of reperfusion) in rats possibly through the decreased cerebral blood flow along with ATP depletion in the ipsilateral hemisphere (dead cell regions) [47]. Another study reported the downregulation of $\mathrm{S}_{1} \mathrm{P}_{1}$ in the kidney $24 \mathrm{~h}$ after ischemia/reperfusion [48]. These two independent reports are consistent with our observation that $\mathrm{S}_{1} \mathrm{P}_{1}$ is downregulated by ischemic challenge. However, the exact mechanism regarding the $\mathrm{S}_{1} \mathrm{P}_{1}$ downregulation following $M / R$ is still unclear and could be pursued as another study. In addition, it is unclear why FTY720 that is supposed to downregulate $\mathrm{S}_{1} \mathrm{P}_{1}$ has a protective effect in cerebral ischemia where $\mathrm{S}_{1} \mathrm{P}_{1}$ is downregulated. Of note, $\mathrm{S}_{1} \mathrm{P}_{1}$ was also reported to be downregulated at the gene level in rat spinal cords of EAE [49] consistent with overactivation by increased S1P levels, while EAE symptoms were reduced by genetic deletion of $\mathrm{S}_{1}$ or its functional antagonism by FTY720, consistent with a critical role for the receptor in MS-like disease [26]. These independent results from studies of MS are consistent with our data in M/R stroke models, which also showed astrocyte activation, $\mathrm{S}_{1} \mathrm{P}_{1}$ downregulation, and the protective effect of FTY720. However, it still remains unclear that S1P receptors with altered expression levels in ischemic brain actually function as pathogenetic factors, which may be tempting to be pursued as a further study.

It is clear that S1P signaling is important for the pathogenesis of cerebral ischemia. This study suggests a possible downregulation of S1P signaling by FTY720, but it is unclear that FTY720 indeed reduces the signaling. It is presumed that the functional antagonism of FTY720 on $\mathrm{S}_{1} \mathrm{P}_{1}$ may be involved in this neuroprotection. In addition, a recent report demonstrates that FTY720 also causes the downregulation of $\mathrm{S}_{3}$ [50], as it does for $\mathrm{S}_{1} \mathrm{P}_{1}$. In this study, $\mathrm{S}_{3}$ was downregulated at mRNA level in the ischemic brain, so it may be possible that FTY720-mediated functional antagonism on $\mathrm{S}_{3}$ may contribute to neuroprotection. Therefore, it would be tempting to find pathogenetic role of $\mathrm{S}_{1} \mathrm{P}_{1}$ or $\mathrm{S}_{3}$ in cerebral ischemia employing genetic or pharmacological tools to study loss of function in the future.

Neuroinflammation that is featured by the activation of neuroglia, such as microglia or astrocytes, in the brain is an important event contributing to brain damage in both initial and recurrent stroke $[1,3-10]$. There are several reports on the anti-inflammatory role of FTY720 in microglial cells $[29,51]$ through as yet unidentified receptor subtype(s). In activated microglia exposed to lipopolysaccharide, FTY720 reduced activation of inflammation-associated signaling molecules [51] and production of proinflammatory cytokines, such as IL-1 $\beta$, IL-6, and TNF- $\alpha$ [29]. In activated astrocytes, FTY720 reduced TNF- $\alpha$-induced ceramide formation [52] even with contrasting results that it did not affect IL-6 production in normal or activated human fetal astrocytes [53]. In this study, FTY720 also reduced neuroglial activation in the ischemic brain. It still remains to elucidate the specific receptor subtypes involved in neuroglial activation. Neuroinflammation is closely linked to blood brain barrier (BBB) disruption and, moreover, S1P signaling has important roles in regulating the $\mathrm{BBB}$, possibly via 2 subtypes of $\mathrm{S} 1 \mathrm{P}$ receptors $\left(\mathrm{S}_{1} \mathrm{P}_{1}\right.$ and $\mathrm{S}_{2} \mathrm{P}_{2}$ ) [54]. It has been reported that S1P signaling modulates $\mathrm{BBB}$ integrity, with contrasting roles depending on receptor subtypes: activation of $\mathrm{S}_{1} \mathrm{P}_{1}$ is linked to enhanced $\mathrm{BBB}$ integrity [55-57] while $\mathrm{S}_{2} \mathrm{P}_{2}$ is linked to increased $\mathrm{BBB}$ permeability [58-60]. Moreover, FTY720 was reported to have protective effects on $\mathrm{BBB}$ damage through the activation of $\mathrm{S}_{1} \mathrm{P}_{1}$ [61]. Therefore, the neuroprotective effect of FTY720 observed in this study may be due to its function on the BBB through $\mathrm{S}_{1}$ because $\mathrm{BBB}$ disruption is also pathogenic in the ischemic brain. However, it is of note that S1P-stimulated responses, including S1P microinjection-induced glial cell activation and potentiated brain damage in the ischemic brain, are attenuated by FTY720 exposure. These results suggest that FTY720 might reduce S1P signaling rather than enhance it, but the exact role of $\mathrm{S} 1 \mathrm{P}$ receptors, especially $\mathrm{S}_{1} \mathrm{P}_{1}$, in the ischemic brain still remains unclear.

\section{Conclusions}

Results from the study of both MS and stroke support S1P receptor-mediated signaling as relevant to these diseases through effects not only on neuroinflammation but also through direct CNS effects involving neuroglial activity, with particular relevance to recurrent stroke through the ability of locally microinjected S1P to potentiate M/R stroke damage. Our data are consistent with the primary effects on $\mathrm{S}_{1}$ and astrocytes; however the role of other S1P receptors and involved cell types in cerebral ischemia awaits future clarification. These data support the actions of S1P receptor modulators for the treatment of stroke, in both the immune system and within the CNS itself, which has therapeutic and mechanistic relevance through targeting these components by brain nonpenetrant versus penetrant compounds.

\section{Conflict of Interests}

The authors have no conflict of interests to declare.

\section{Acknowledgments}

This work was supported by grants from the National Research Foundation (NRF) and Ministry of Health and Welfare funded by the Korean Government to Ji Woong Choi (NRF-2013R1A1A1A05005520 and HI13C18200000) and an academic grant from Novartis (Jerold Chun). The authors 
thank Dr. Hope Mirendil and Ms. Danielle Jones for editorial assistance.

\section{References}

[1] I. M. Shah, I. M. Macrae, and M. Di Napoli, "Neuroinflammation and neuroprotective strategies in acute ischaemic strokefrom bench to bedside," Current Molecular Medicine, vol. 9, no. 3, pp. 336-354, 2009.

[2] K. P. Doyle, R. P. Simon, and M. P. Stenzel-Poore, "Mechanisms of ischemic brain damage," Neuropharmacology, vol. 55, no. 3 , pp. 310-318, 2008.

[3] V. Pizza, A. Agresta, C. W. D’Acunto, M. Festa, and A. Capasso, "Neuroinflamm-aging and neurodegenerative diseases: an overview," CNS \& Neurological Disorders-Drug Targets, vol. 10, no. 5, pp. 621-634, 2011.

[4] M. Rodríguez-Yáñez and J. Castillo, "Role of inflammatory markers in brain ischemia," Current Opinion in Neurology, vol. 21, no. 3, pp. 353-357, 2008.

[5] P. Couillard, A. Y. Poppe, and S. B. Coutts, "Predicting recurrent stroke after minor stroke and transient ischemic attack," Expert Review of Cardiovascular Therapy, vol. 7, no. 10, pp. 1273-1281, 2009.

[6] M. N. Nguyen-Huynh and S. C. Johnston, "Evaluation and management of transient ischemic attack: an important component of stroke prevention," Nature Clinical Practice Cardiovascular Medicine, vol. 4, no. 6, pp. 310-318, 2007.

[7] D. Clark, U. I. Tuor, R. Thompson et al., "Protection against recurrent stroke with resveratrol: endothelial protection," PLoS ONE, vol. 7, no. 10, Article ID e47792, 2012.

[8] J.-C. Lee, G.-S. Cho, J. K. Hye et al., "Accelerated cerebral ischemic injury by activated macrophages/microglia after lipopolysaccharide microinjection into rat corpus callosum," Glia, vol. 50, no. 2, pp. 168-181, 2005.

[9] D.-W. Kang, S.-H. Yoo, S. Chun et al., "Inflammatory and hemostatic biomarkers associated with early recurrent ischemic lesions in acute ischemic stroke," Stroke, vol. 40, no. 5, pp. 1653$1658,2009$.

[10] N. Kuriyama, T. Mizuno, M. Kita et al., "Predictive markers of blood cytokine and chemokine in recurrent brain infarction," Journal of Interferon and Cytokine Research, vol. 29, no. 11, pp. 729-734, 2009.

[11] M. S. V. Elkind, W. Tai, K. Coates, M. C. Paik, and R. L. Sacco, "Lipoprotein-associated phospholipase $\mathrm{A}_{2}$ activity and risk of recurrent stroke," Cerebrovascular Diseases, vol. 27, no. 1, pp. 4250, 2009.

[12] Z. G. Nadareishvili, H. Li, V. Wright et al., "Elevated proinflammatory $\mathrm{CD} 4{ }^{+} \mathrm{CD} 28^{-}$lymphocytes and stroke recurrence and death," Neurology, vol. 63, no. 8, pp. 1446-1451, 2004.

[13] P. Welsh, G. D. O. Lowe, J. Chalmers et al., "Associations of proinflammatory cytokines with the risk of recurrent stroke," Stroke, vol. 39, no. 8, pp. 2226-2230, 2008.

[14] W. Whiteley, C. Jackson, S. Lewis et al., "Association of circulating inflammatory markers with recurrent vascular events after stroke: a prospective cohort study," Stroke, vol. 42, no. 1, pp. $10-$ $16,2011$.

[15] S. Spiegel and S. Milstien, "The outs and the ins of sphingosine1-phosphate in immunity," Nature Reviews Immunology, vol. 11, no. 6, pp. 403-415, 2011.

[16] Y. Kihara, M. Maceyka, S. Spiegel, and J. Chun, "Lysophospholipid receptor nomenclature review: IUPHAR review 8," British Journal of Pharmacology, vol. 171, no. 15, pp. 3575-3594, 2014.
[17] J. Chun and V. Brinkmann, "A mechanistically novel, first oral therapy for multiple sclerosis: the development of fingolimod (FTY720, Gilenya)," Discovery Medicine, vol. 12, no. 64, pp. 213228, 2011.

[18] V. Brinkmann, A. Billich, T. Baumruker et al., "Fingolimod (FTY720): discovery and development of an oral drug to treat multiple sclerosis," Nature Reviews Drug Discovery, vol. 9, no. 11, pp. 883-897, 2010.

[19] J. Chun and H.-P. Hartung, "Mechanism of action of oral fingolimod (FTY720) in multiple sclerosis," Clinical Neuropharmacology, vol. 33, no. 2, pp. 91-101, 2010.

[20] J. A. Cohen and J. Chun, "Mechanisms of fingolimod's efficacy and adverse effects in multiple sclerosis," Annals of Neurology, vol. 69, no. 5, pp. 759-777, 2011.

[21] J. W. Choi and J. Chun, "Lysophospholipids and their receptors in the central nervous system," Biochimica et Biophysica Acta, vol. 1831, no. 1, pp. 20-32, 2013.

[22] D. Nayak, Y. Huo, W. X. T. Kwang et al., "Sphingosine kinase 1 regulates the expression of proinflammatory cytokines and nitric oxide in activated microglia," Neuroscience, vol. 166, no. 1, pp. 132-144, 2010.

[23] S. D. Sorensen, O. Nicole, R. D. Peavy et al., "Common signaling pathways link activation of murine PAR-1, LPA, and S1P receptors to proliferation of astrocytes," Molecular Pharmacology, vol. 64, no. 5, pp. 1199-1209, 2003.

[24] S. S. Dusaban, N. H. Purcell, E. Rockenstein et al., "Phospholipase $\mathrm{C} \varepsilon$ links $\mathrm{G}$ protein-coupled receptor activation to inflammatory astrocytic responses," Proceedings of the National Academy of Sciences of the United States of America, vol. 110, no. 9, pp. 3609-3614, 2013.

[25] C. S. Garris, L. Wu, S. Acharya et al., "Defective sphingosine 1phosphate receptor $1\left(\mathrm{~S}_{1} \mathrm{P}_{1}\right)$ phosphorylation exacerbates $\mathrm{T}_{\mathrm{H}} 17$ mediated autoimmune neuroinflammation," Nature Immunology, vol. 14, no. 11, pp. 1166-1172, 2013.

[26] J. W. Choi, S. E. Gardell, D. R. Herr et al., "FTY720 (fingolimod) efficacy in an animal model of multiple sclerosis requires astrocyte sphingosine 1-phosphate receptor 1 (S1P1) modulation," Proceedings of the National Academy of Sciences of the United States of America, vol. 108, no. 2, pp. 751-756, 2011.

[27] H. J. Kim, V. E. Miron, D. Dukala et al., "Neurobiological effects of sphingosine 1-phosphate receptor modulation in the cuprizone model," The FASEB Journal, vol. 25, no. 5, pp. 15091518, 2011.

[28] V. E. Miron, S. K. Ludwin, P. J. Darlington et al., "Fingolimod (FTY720) enhances remyelination following demyelination of organotypic cerebellar slices," The American Journal of Pathology, vol. 176, no. 6, pp. 2682-2694, 2010.

[29] H. Noda, H. Takeuchi, T. Mizuno, and A. Suzumura, "Fingolimod phosphate promotes the neuroprotective effects of microglia," Journal of Neuroimmunology, vol. 256, no. 1-2, pp. 13-18, 2013.

[30] Y.-P. Wu, K. Mizugishi, M. Bektas, R. Sandhoff, and R. L. Proia, "Sphingosine kinase 1/S1P receptor signaling axis controls glial proliferation in mice with Sandhoff disease," Human Molecular Genetics, vol. 17, no. 15, pp. 2257-2264, 2008.

[31] A. Kimura, T. Ohmori, Y. Kashiwakura et al., "Antagonism of sphingosine 1-phosphate receptor-2 enhances migration of neural progenitor cells toward an area of brain infarction," Stroke, vol. 39, no. 12, pp. 3411-3417, 2008.

[32] B. Czech, W. Pfeilschifter, N. Mazaheri-Omrani et al., "The immunomodulatory sphingosine 1-phosphate analog FTY720 
reduces lesion size and improves neurological outcome in a mouse model of cerebral ischemia," Biochemical and Biophysical Research Communications, vol. 389, no. 2, pp. 251-256, 2009.

[33] Y. Hasegawa, H. Suzuki, T. Sozen, W. Rolland, and J. H. Zhang, "Activation of sphingosine 1-phosphate receptor-1 by FTY720 is neuroprotective after ischemic stroke in rats," Stroke, vol. 41, no. 2, pp. 368-374, 2010.

[34] W. Pfeilschifter, B. Czech-Zechmeister, M. Sujak et al., "Activation of sphingosine kinase 2 is an endogenous protective mechanism in cerebral ischemia," Biochemical and Biophysical Research Communications, vol. 413, no. 2, pp. 212-217, 2011.

[35] T. Shichita, Y. Sugiyama, H. Ooboshi et al., "Pivotal role of cerebral interleukin-17-producing T cells in the delayed phase of ischemic brain injury," Nature Medicine, vol. 15, no. 8, pp. $946-$ 950, 2009.

[36] Y. Wei, M. Yemisci, H.-H. Kim et al., "Fingolimod provides long-term protection in rodent models of cerebral ischemia," Annals of Neurology, vol. 69, no. 1, pp. 119-129, 2011.

[37] Y. Fu, J. Hao, N. Zhang et al., "Fingolimod for the treatment of intracerebral hemorrhage: a 2-arm proof-of-concept study," JAMA Neurology, vol. 71, no. 9, pp. 1092-1101, 2014.

[38] H. Nagasawa and K. Kogure, "Correlation between cerebral blood flow and histologic changes in a new rat model of middle cerebral artery occlusion," Stroke, vol. 20, no. 8, pp. 1037-1043, 1989.

[39] J. E. Han, E.-J. Lee, E. Moon, J. H. Ryu, J. W. Choi, and H.-S. Kim, "Matrix metalloproteinase- 8 is a novel pathogenetic factor in focal cerebral ischemia," Molecular Neurobiology, 2014.

[40] J. Chen, P. R. Sanberg, Y. Li et al., "Intravenous administration of human umbilical cord blood reduces behavioral deficits after stroke in rats," Stroke, vol. 32, no. 11, pp. 2682-2688, 2001.

[41] J. Jordán, T. Segura, D. Brea, M. F. Galindo, and J. Castillo, "Inflammation as therapeutic objective in stroke," Current Pharmaceutical Design, vol. 14, no. 33, pp. 3549-3564, 2008.

[42] P. J. Lindsberg and A. J. Grau, "Inflammation and infections as risk factors for ischemic stroke," Stroke, vol. 34, no. 10, pp. 25182532, 2003.

[43] N. Blondeau, Y. Lai, S. Tyndall et al., "Distribution of sphingosine kinase activity and mRNA in rodent brain," Journal of Neurochemistry, vol. 103, no. 2, pp. 509-517, 2007.

[44] B. K. Wacker, T. S. Park, and J. M. Gidday, "Hypoxic preconditioning-induced cerebral ischemic tolerance: role of microvascular sphingosine kinase 2," Stroke, vol. 40, no. 10, pp. 3342-3348, 2009.

[45] H. Liu, M. Sugiura, V. E. Nava et al., "Molecular cloning and functional characterization of a novel mammalian sphingosine kinase type 2 isoform," The Journal of Biological Chemistry, vol. 275, no. 26, pp. 19513-19520, 2000.

[46] B. K. Wacker, A. B. Freie, J. L. Perfater, and J. M. Gidday, "Junctional protein regulation by sphingosine kinase 2 contributes to blood-brain barrier protection in hypoxic preconditioninginduced cerebral ischemic tolerance," Journal of Cerebral Blood Flow and Metabolism, vol. 32, no. 6, pp. 1014-1023, 2012.

[47] Y. Hasegawa, H. Suzuki, O. Altay, W. Rolland, and J. H. Zhang, "Role of the sphingosine metabolism pathway on neurons against experimental cerebral ischemia in rats," Translational Stroke Research, vol. 4, no. 5, pp. 524-532, 2013.

[48] A. S. Awad, H. Ye, L. Huang et al., "Selective sphingosine 1phosphate 1 receptor activation reduces ischemia-reperfusion injury in mouse kidney," American Journal of Physiology-Renal Physiology, vol. 290, no. 6, pp. F1516-F1524, 2006.
[49] R. Van Doorn, J. Van Horssen, D. Verzijl et al., "Sphingosine 1phosphate receptor 1 and 3 are upregulated in multiple sclerosis lesions," Glia, vol. 58, no. 12, pp. 1465-1476, 2010.

[50] C. Nussbaum, S. Bannenberg, P. Keul et al., "Sphingosine-1phosphate receptor 3 promotes leukocyte rolling by mobilizing endothelial P-selectin," Nature Communications, vol. 6, article 6416, 2015.

[51] R. Cipriani, J. C. Chara, A. Rodríguez-Antigüedad, and C. Matute, "FTY720 attenuates excitotoxicity and neuroinflammation," Journal of Neuroinflammation, vol. 12, article 86, 2015.

[52] R. van Doorn, P. G. Nijland, N. Dekker et al., "Fingolimod attenuates ceramide-induced blood-brain barrier dysfunction in multiple sclerosis by targeting reactive astrocytes," Acta Neuropathologica, vol. 124, no. 3, pp. 397-410, 2012.

[53] C. Wu, S. Y. Leong, C. S. Moore et al., "Dual effects of daily FTY720 on human astrocytes in vitro: relevance for neuroinflammation," Journal of Neuroinflammation, vol. 10, article 41, 2013.

[54] B. Prager, S. F. Spampinato, and R. M. Ransohoff, "Sphingosine 1-phosphate signaling at the blood-brain barrier," Trends in Molecular Medicine, vol. 21, no. 6, pp. 354-363, 2015.

[55] K. Gaengel, C. Niaudet, K. Hagikura et al., "The sphingosine1-phosphate receptor S1PR1 restricts sprouting angiogenesis by regulating the interplay between VE-cadherin and VEGFR2," Developmental Cell, vol. 23, no. 3, pp. 587-599, 2012.

[56] Y. Liu, R. Wada, T. Yamashita et al., "Edg-1, the G proteincoupled receptor for sphingosine-1-phosphate, is essential for vascular maturation," The Journal of Clinical Investigation, vol. 106, no. 8, pp. 951-961, 2000.

[57] D. Zhu, Y. Wang, I. Singh et al., "Protein S controls hypoxic/ischemic blood-brain barrier disruption through the TAM receptor Tyro3 and sphingosine 1-phosphate receptor," Blood, vol. 115, no. 23, pp. 4963-4972, 2010.

[58] L. Cruz-Orengo, B. P. Daniels, D. Dorsey et al., "Enhanced sphingosine-1-phosphate receptor 2 expression underlies female CNS autoimmunity susceptibility," Journal of Clinical Investigation, vol. 124, no. 6, pp. 2571-2584, 2014.

[59] A. Skoura, J. Michaud, D.-S. Im et al., "Sphingosine-1-phosphate receptor-2 function in myeloid cells regulates vascular inflammation and atherosclerosis," Arteriosclerosis, Thrombosis, and Vascular Biology, vol. 31, no. 1, pp. 81-85, 2011.

[60] G. Zhang, L. Yang, G. S. Kim et al., "Critical role of sphingosine1-phosphate receptor 2 (S1PR2) in acute vascular inflammation," Blood, vol. 122, no. 3, pp. 443-455, 2013.

[61] S. F. Spampinato, B. Obermeier, A. Cotleur et al., "Sphingosine 1 phosphate at the blood brain barrier: can the modulation of slp receptor 1 influence the response of endothelial cells and astrocytes to inflammatory stimuli?" PLOS ONE, vol. 10, no. 7, Article ID e0133392, 2015. 


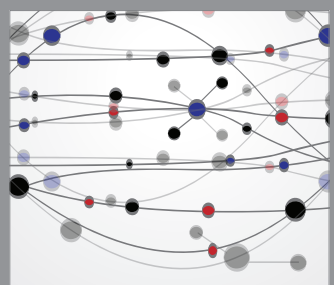

The Scientific World Journal
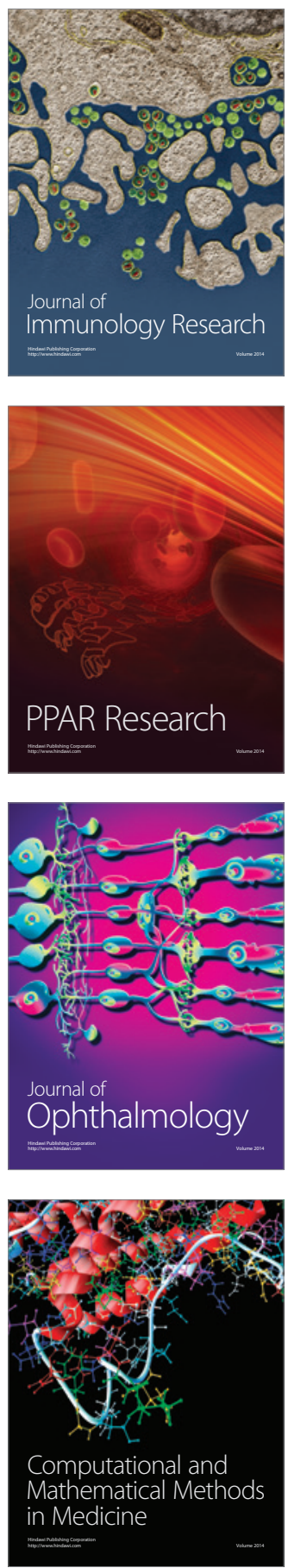

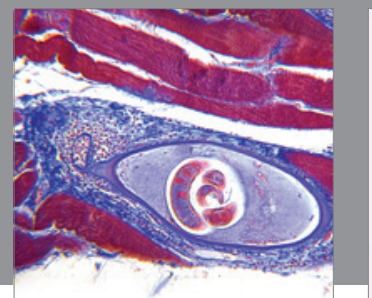

Gastroenterology

Research and Practice
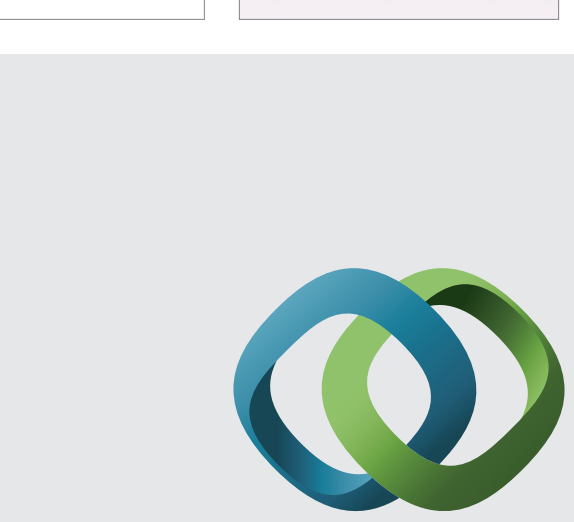

\section{Hindawi}

Submit your manuscripts at

http://www.hindawi.com
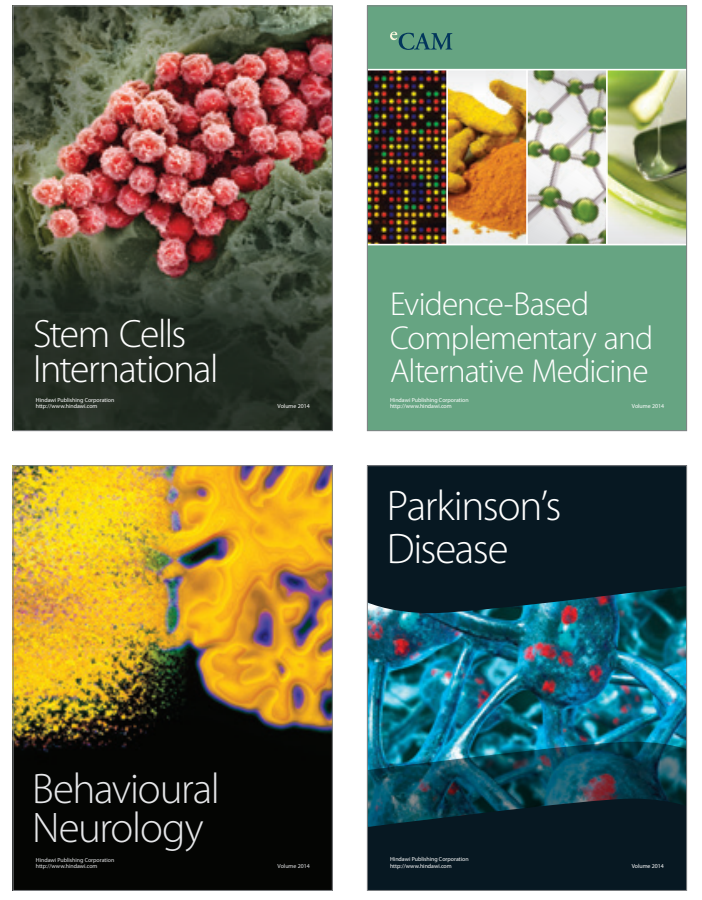
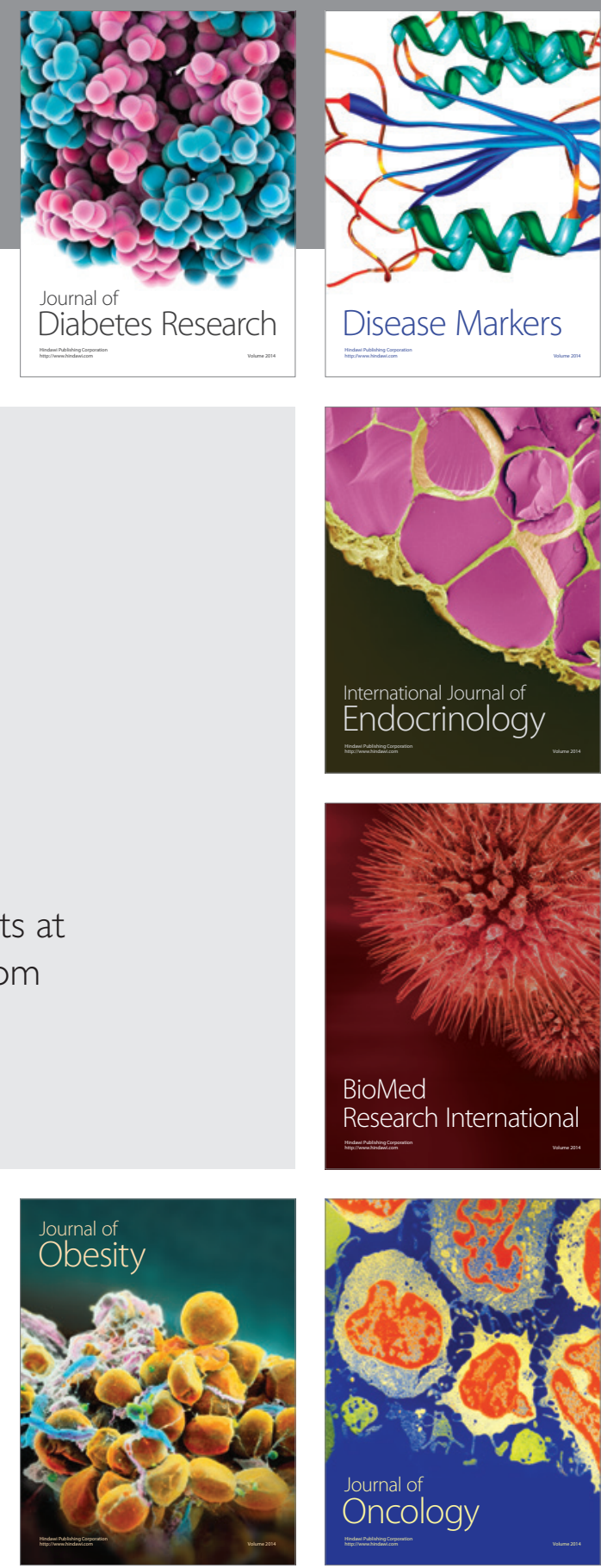

Disease Markers
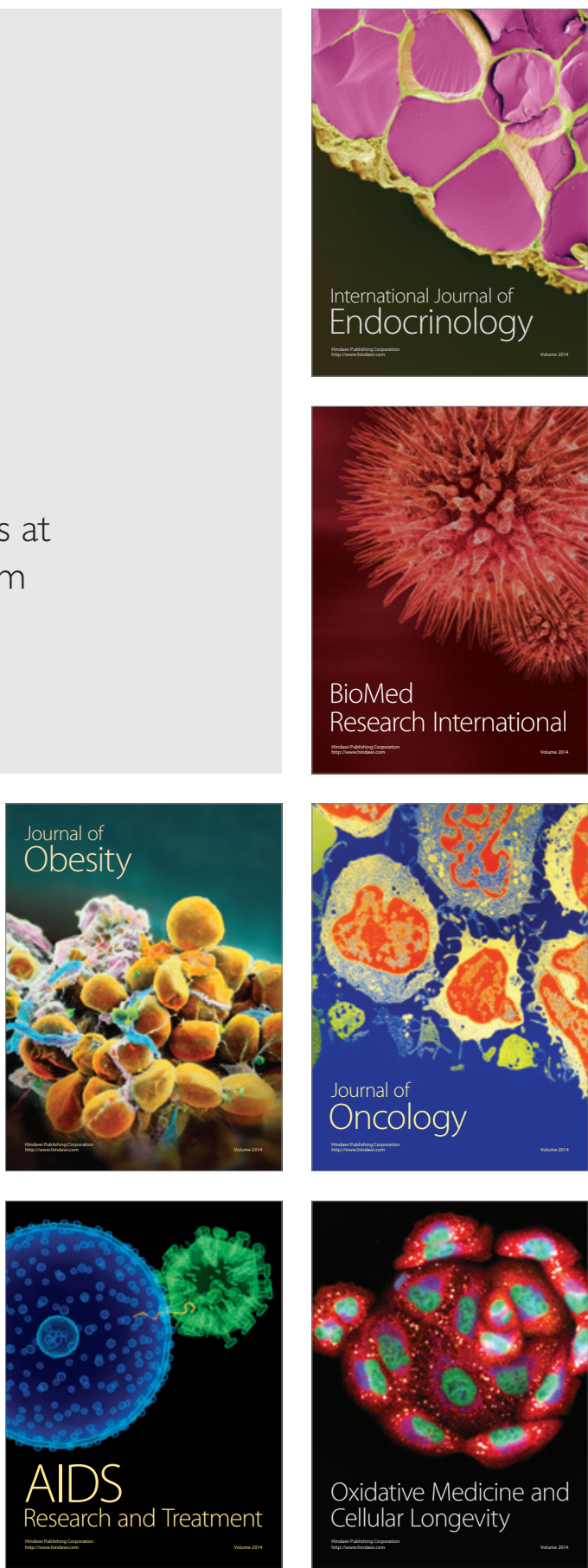